\title{
LA ILUMINACIÓN NATURAL DE LA CIENCIA DE THALES DE MILETO A LA NUEVA ALIANZA DE PRIGOGINE Y STENGERS
}

Rubén Edgar Corvalán ${ }^{1}$; Alicia Susana Cuevas²; Alicia Itatí Amarilla ${ }^{3}$

Resumen: El presente es un abordaje de la iluminación intelectual desde la ingeniería y la administración en base a amplias revisiones bibliográficas. Y siendo la Filosofía considerada la madre de todas las ciencias, dándose en este tiempo un resurgir de la consideración de esta, en la búsqueda de conocer los orígenes de las distintas ramas de las ciencias de hoy, que se han expandido hasta niveles nunca pensados como la big data o la inteligencia artificial. Este trabajo ha sido organizado a través de una línea de tiempo básica donde se destacan los principales filósofos de la historia hasta la actualidad y las corrientes filosóficas en relación con la ciencia. Resaltando sus similitudes y contradicciones principalmente en la relación de la ciencia con la naturaleza.

\section{Introducción}

El objeto motivador que mueve el pensamiento de este trabajo, es descubrir dentro del proceso histórico de la filosofía de la ciencia, el pensamiento de los principales autores y como consideraban, si lo hacían, su relación con la naturaleza, de manera directa o simplemente de manera tangencial, partiendo desde el mismo concepto, pasando por los distintos filósofos de la historia, hasta nuestros días con la Nueva Alianza de Ilya Prigogine (Premio Nobel de Química 1977) e Isabelle Stengers (Gran Premio de Filosofía de la academia Francesa 1993). Hasta la encíclica laudato Si del Papa Francisco (2015).

Partimos del término Filosofía; de origen griego, se compone de dos vocablos: philos ("amor") y sophia ("pensamiento, sabiduría, conocimiento"). Por lo tanto, la filosofía es el "amor por el conocimiento". Al igual que la religión, la filosofía se centra en las cuestiones últimas de la existencia humana. En cambio, a diferencia de la religión, no se basa en una revelación divina o en la fe, sino que lo hace en la razón. De esta forma, la filosofía puede ser definida

\footnotetext{
1. Magister en Administración de Negocios -M.B.A. (Máster in Business Administratión) Email: rubenpstt@yahoo.com.ar FACENA - Universidad Nacional del Nordeste. Argentina.

2. Especialista en Salud Social y Comunitaria

3. Especialista en Gestión de las Relaciones del Trabajo.
} 
como el análisis racional del sentido último de la existencia humana, tanto individual como colectiva, fundado en la comprensión del ser. Al inicio de la filosofía tal como la conocemos, podemos identificar cuatro periodos; la filosofía presocrática que no tenía escritura por ello lo que nos llega es a través de otros escritores, pero que tuvieron una influencia histórica, asimismo los sofistas, la ática y la post-aristotélica.

Etapas todas ellas donde tomaron protagonismo grandes pensadores que actualmente siguen estudiándose y que se han convertido en pilares básicos de la historia de la filosofía. Este sería, por ejemplo, el caso de Platón, quien fue seguidor de Sócrates, quien se destacó por realizar numerosas obras donde hizo especial hincapié en lo que es la teoría de las ideas y de las formas. En concreto lo que se consensuó es que cada idea es inmutable y única y que los seres, de lo que es el mundo sensible, se caracterizan por ser imperfectos y deficientes. Cuestiones todas ellas que adquirieron gran valor entre la filosofía como lo demostró Platón en su célebre mito de la caverna donde analiza en profundidad la diferencia entre realidad y conocimiento. Además de este pensador fue fundamental Aristóteles, quien fuera discípulo del anterior. Una figura que está considerada, entre otras cosas, como el padre de la Lógica. Debiéndose considerar también que a diferencia de la ciencia, que es más eficaz para resolver problemas, la filosofía solo profundiza el conocimiento, desde la primera separación entre espíritu y physis (multiplicidad y cambio), se la puede considerar una meta reflexión: reflexión sobre la reflexión: Que es la realidad?; Qué sentido tiene la vida?; Que cabe esperar?; Que debo conocer?; Que debo saber?; Que debo hacer?; Que cabe esperar?, Que es el hombre?...

Leibniz y Schopenhauer con el principio de razón suficiente: hacen una delimitación de lo que es una explicación; explicar es sacar a la luz lo que está oscuro, sacar el velo, describir, distinguir, entender como es. Las preguntas y respuestas estarán dirigidas, no místicamente o dogmáticamente: ¿Por qué ocurre lo que ocurre? ¿Por qué es lo que es? ¿Por qué es? "todo objeto debe tener una razón suficiente que lo explique". Lo que es, es por alguna razón, "nada existe sin una causa o razón determinante".

\section{Metodología}

El Diseño metodológico de la investigación cualitativa, es de una investigación histórica, como una búsqueda critica de la verdad que se sustenta en los acontecimientos pasados, que permitieron conocer el pensamiento en la búsqueda de la verdad y el conocimiento de los principales filósofos de la ciencia. Se trata también de una investigación descriptiva, ya que trabaja sobre realidades de hecho, con la característica de intentar presentar una interpretación correcta desde las distintas etapas filosóficas, desde un nomenclador común: la iluminación de la naturaleza. Se trata de un estudio correlacional, por su valor explicativo, aunque parcial, evaluando el grado de relación, pero no necesariamente explicando las causas que llevaron a cada conclusión de las líneas de pensamiento y sus formas. Es una 
investigación no experimental; longitudinal, extendida a través de los tiempos históricos. Realizada a través de revisión bibliográfica, basadas en una idea generatriz de línea de tiempo. Los alcances son la de simplemente descubrir una correlación dentro de una característica de los procesos cíclicos de la historia de la filosofía del conocimiento.

\section{Antecedentes y Consideraciones}

E1 extraordinario Thales de Mileto (nació en la actual Turquía, 624 a.C. al 548 a.C.) Filósofo y matemático griego. En su juventud viajó a Egipto, donde aprendió geometría y astronomía de los sacerdotes de Menfis, que posteriormente le permitiría enseñar estas ciencias con el nombre de astrosofía. Es considerado el padre de la filosofía occidental. Esto se debe a que se le atribuye el haber intentado, por primera vez de manera seria, explicar racionalmente los fenómenos del mundo. Antes de Thales, predominaban todavía las explicaciones místicas a los fenómenos. Diógenes Laercio, relevante historiador griego de filosofía clásica nacido alrededor del siglo III, afirmó que Thales no dejó nada escrito. Simplicio, por su parte, le atribuyó la obra Astrología náutica. Según Aristóteles, Thales sostuvo que el origen de todas las cosas partiendo de la naturaleza es el agua, el elemento primero. Especuló que Thales llegó a tal conclusión debido a que el agua está presente en los alimentos y en todos los seres vivos que observó. Aristóteles lo consideraba el primero de los "filósofos de la naturaleza". La esperanza es el único bien común a todos los hombres; los que han perdido todo,

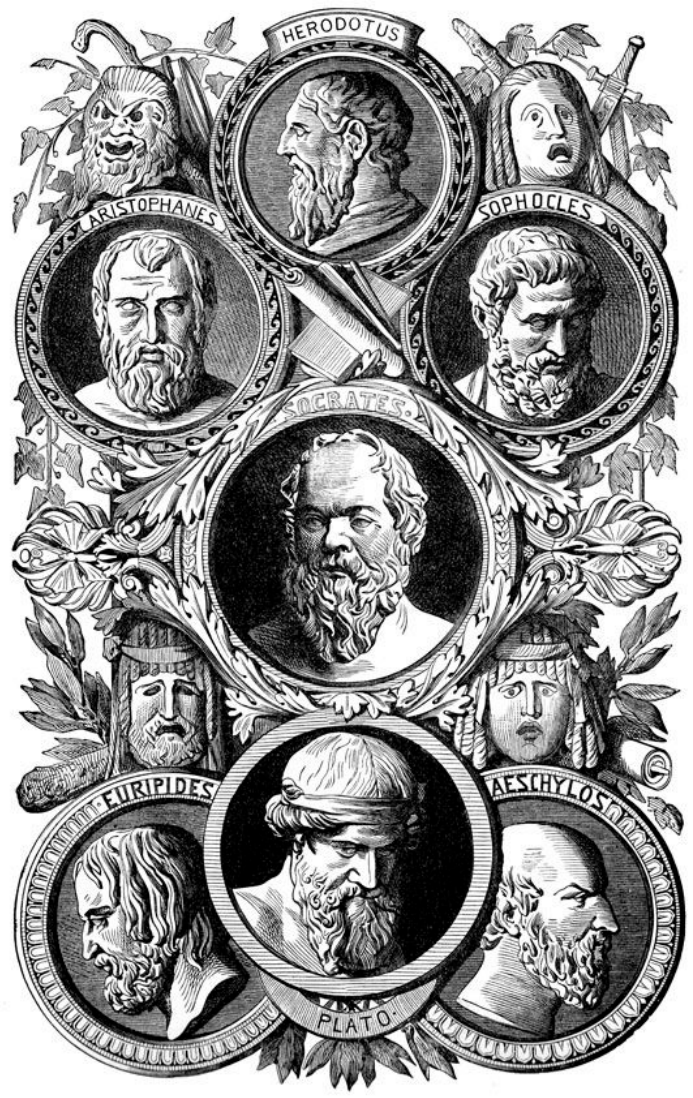

la poseen aún. Definió por primera vez el término arge, que es principio fundamento y unidad.

$\mathrm{Su}$ discípulo Anaximandro: Filósofo, matemático y astrónomo griego. Nació en Mileto en el 610 a 545 a.c. Fue miembro de la escuela de Mileto, donde sucedió a Thales en la dirección de la misma. Como político desempeñó cargos importantes. Se dedicó a múltiples investigaciones, como la del estudio de la tierra que él imaginaba como un cilindro inmóvil. Considero al Apeyron como el origen de todas las cosas, lo que no tiene límite. El Arge: si todas las cualidades se consideran de acuerdo a su opuesto, éste tiene que ser algo que no pueda buscar un 
opuesto. La nada como el infinito son construcciones imaginarias del momento. Lo que no tenga determinación, en vez de nada lo llamamos Apeyron: lo indeterminado.

Las características que se tienen que entender en las explicaciones son en base a los cinco sentidos y la reflexión racional. Todos los seres derivan de otros seres más antiguos por transformaciones sucesivas. De aquí surgieron tres ideas: holismo, ecologismo, evolucionismo. A este filosofo le sucede Anaxímenes: 588 a 524 a. c. Quien escribió el peri physeos, sobre la naturaleza. Fue el primero en analizar el cómputo geométrico de las sombras para medir las partes y divisiones del día. Basado en la naturaleza, en este caso en el aire, argumentaba que por condensación se forman las nubes, que sí se condensan se forma el agua, su condensación dará lugar al hielo, la tierra si se condensa da lugar a las piedras y los minerales, lo mismo ocurrirá con el proceso inverso, la rarefacción. Consideraba que como el alma, que es aire, nos conserva en la vida, el aliento y el aire envuelven y mantienen al mundo.

Uno de los más reconocidos por las denominadas ciencias duras, fue Pitágoras, 569 a 475 a. c. Filósofo y matemático griego, considerado el primer matemático puro. Es el fundador de la hermandad Pitagórica, una sociedad que se interesaba también en la medicina, la cosmología, la filosofía, la ética y política, entre otras disciplinas. El Pitagórico formuló principios que influyeron tanto en Platón como en Aristóteles y de manera más general, en el posterior desarrollo de la matemática y en la filosofía racional en occidente. Consideró el dualismo entre la apariencia y la realidad, y que la matemática explicaría la verdadera realidad, el conocimiento da la verdadera razón por medio de las leyes matemáticas, el firmamento es armonía y número. Entre sus obras se destacan: el teorema de Pitágoras, sólidos perfes, ángulos interiores de un triángulo, entre otras. También Parménides quien vivió entre 540 a 470 a. c. Escribió sobre la iluminación de la naturaleza, al poner su doctrina a partir del reconocimiento de dos caminos para acceder al mismo: la vía de la verdad y la vía de la opinión, siendo sólo el primero un camino transitable, siendo el segundo objeto de continuas contradicciones y apariencia de conocimiento. Decía la música que no describa algo no es más que ruido. Todo cambia, si yo soy yo y nada sale, sí cambio, y soy yo, solo hay yo, es decir dos yo, todos son diferentes yo, en un principio de contradicción. Asimismo reconocía Heráclito 535 a 484 a. c. que la realidad es una lucha entre opuestos, dando ejemplos desde la naturaleza, el fuego es lo que no cambia aunque le agreguen cosas sigue siendo fuego. La realidad es lucha, es tensión, si la tesis se convierte en contra tesis, de la lucha de las dos sale la síntesis y su antítesis, y así sucesivamente, por lo tanto persiste la sucesión de argumentos y contra argumentos. Incorporó el concepto del devenir considerándolo una realidad básica subyacente a todas las cosas. Afirmaba que el fundamento de todas las cosas está en un cambio incesante. Todo se transforma en un proceso de nacimiento y destrucción 
al que nada escapa. Si no se espera lo inesperado no lo reconocerás cuando llegué.

Asimismo consideró Anaxágoras 500 al 428 a.c. que el número de principios es infinito, que todo está mezclado excepto la inteligencia, la inteligencia existe pura y sin mezcla, el ser no puede generarse ni corromperse; no por nacimiento ni destrucción, sino una separación o mezcla de las cosas que existen. Existe un número infinito de partes, poseyendo las características de la inmutabilidad. Consideraba que la inteligencia es lo más puro de todas las cosas. Que tiene un conocimiento total de cada cosa y es la máxima fuerza. Así Demócrito 460 a 370 a. c. tomó como primeros principios a lo lleno y lo vacío, al ser o no ser. El ser son los átomos, todas las cosas están formadas por átomos, incluso las almas. La virtud consiste en el equilibrio de las pasiones, logrado a través del saber y la prudencia. Destaco que la felicidad no reside fuera de nosotros sino en nuestra parte más noble en nuestra propia alma. Escribió libros éticos, físicos, matemáticos, filológicos y técnicos.

Asimismo Sócrates 470 a 399 a.c. Identifica la virtud como el conocimiento. Bastaba el conocimiento de lo justo para obrar correctamente. Las malas acciones son producto del desconocimiento. Hace lo mismo que los sofistas, ayudando a sacar a relucir el bien de su ciudad: Atenas. No escribió propiamente ninguna obra, decía que el escribir era ya una limitación al pensamiento, debido a que al escribir ya se producía una traducción y al volver a releerla una nueva traducción que va desdibujando la idea original. Decía que la verdadera sabidu- ría está en reconocer la propia ignorancia. Volviendo a Platón 427 a 347 a. c. escribió las ideas de Sócrates, y defendió el dualismo ontológico qué consiste en la existencia de dos mundos opuestos: el mundo de las ideas el cual consta de realidades universales y es eterno, y el mundo sensible que consta de realidades particulares y en el que se producen cambios. En la búsqueda de la definición del bien, funda la Academia y su discípulo fue Aristóteles. Así Platón eligió el diálogo como forma de expresión de su pensamiento. Proclamando que buscando el bien de nuestros semejantes, encontramos el nuestro. El maestro Aristóteles 384 a 322 a.c. escribió sobre todo el conocimiento de su época, creó la lógica. Fundó su escuela denominada Liceo. Dividió el conocimiento en tres aspectos: teórico (¿Qué es?), práctico (ética y política) y productivo (técnico). La sabiduría no debe ser utilitaria, no se

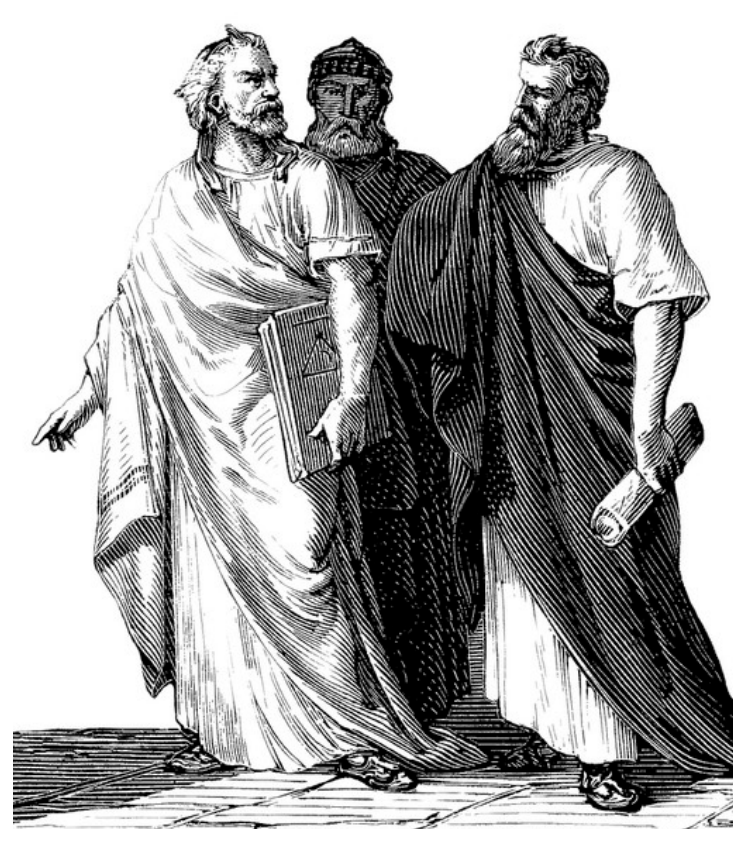


debe querer por otra cosa que no sea su propio valor. Argumentaba que lo importante del ser humano es su esencia, y gustaba teorizar sobre la metafísica. Estudió los cambios y sus causas en el estudio de la physis. Definió las cuatro causas para analizar el conocimiento: causa del ser: 1- material: de qué está hecho; 2-formal: la forma que tiene: animal, humana, astro, etc. 3- causa eficiente: de donde sale el impulso, generación, transformación. y 4 causa final: realización de la esencia. El sabio no dice todo lo que piensa, pero piensa todo lo que dice.

En la Edad media, se tradujo al Cristianismo lo reflexionado por Aristóteles y Platón. Trocando el concepto del motor inmóvil, que da origen a todos los movimientos, por Dios. Denominándose a este movimiento de adaptación de Aristóteles al cristianismo: Escolástica. En este periodo se crean las universidades, siendo las primeras las de Oxford, Bolonia, Salamanca y Paris. Fue durante los siglos XII y XIII, que se desarrolla la escolástica, y se avanza del feudalismo a sociedades modernas; con la mezcla del islam y el cristianismo surge el renacimiento, luego con independencia de la explicación religiosa, se vuelve a Aristóteles en la observación, clasificación o taxonomía. Igualmente se desarrolla un pensamiento teológico, que se aleja de la religiosidad social, por sus grandes argumentaciones sobre por qué es más que la razón.

Tomás de Aquino 1225 -1274: exhibía dos órdenes de conocimiento, el natural que procede de la razón humana que da lugar a la filosofía y el sobrenatural, que procede de la revelación y de la fe y es un conocimien- to fusco. Argumentaba que ambos proceden en último término de Dios, por lo que no podría haber contradicción. Por ello se desprende que "Tratad a los demás, como deseáis que los demás os traten a vosotros". Cercano a este periodo Juan Burindan 1300 - 1358 que nació en Betune (Francia) y cursó estudios en la universidad de París, donde tuvo como maestro al filósofo escolástico inglés Guillermo de Ockham, en 1350 explica el movimiento con el Ímpetu, expone que el aire no es un motor sino un freno al movimiento, por rozamiento, en contraposición a Aristóteles, que ponía en el aire el motor. También es celebre la paradoja del asno de Burindan, donde explica el libre albedrio para la toma de decisiones de esta manera: el animal no podía tomar una decisión de que montón de heno alimentarse, ya que se encontraba a igual distancia de ellos y los dos eran iguales, por lo que al no poder tomar una decisión lógica el mismo se moría de hambre. Pero por el libre albedrio podía tomar una decisión, sin razón, de cual heno alimentarse.

Así se pueden distinguir distintas Formas del Conocimiento: la Magia como la del Médico Paracelso que nació en Suiza en 1493 - 1541, fue alquimista, quien consideraba al universo como un gran ser vivo; como el actual concepto de la gaia. La Filosofía Natural de Giordano Bruno y Campanella Telesio, coinciden en que la naturaleza y el hombre poseen lenguajes diferenciados. La Ciencia de la edad moderna rechazaba a la naturaleza como un gran ser vivo, se la comparaba como una gran maquinaria, como un reloj, que da la medida del tiempo. 
Otro gran pensador fue Leonardo Da Vinci, quien es considerado por sus conceptos y trayectoria el segundo Aristóteles. Expuso los Postulados de la ciencia moderna: 1- Empirismo: En la naturaleza existen condiciones que se mantienen relativamente constantes, es decir que duran un periodo determinado, algunos fenómenos no cambian sus características básicas, al menos de manera apreciable. 2- Mecanicismo: la metáfora del reloj, que reemplaza al orgánico, la ciencia crece con esta idea de sencillez y precisión, el ojo es la ventana del alma (Da Vinci), son observaciones objetivas, dejando de lado emociones, pasiones y sentimientos. 3-Matematización de lo real, como lenguaje oculto de la naturaleza, la misma puede ser descripta matemáticamente. Como Ejemplo de esto: Numero de Fibonacci, numero phi, numero e, entre otros.

Aparece luego el Objetivismo: Una verdad para todos los seres racionales, independientemente de todas las personas que piensan, teoría sobre la verdad que podemos conocerla (no necesariamente que la conozcamos, si nos acercamos o alejamos de ella). Y el Relativismo: Tesis filosóficas, que hay verdades pero no para cada uno que piensa, que dependen de factores físicos, culturales, tradicionales, etc., que influyen en lo que se considera verdad y por lo tanto en lo que se considera la realidad. El Escepticismo: Es la evolución del relativismo, no existe la verdad, y si existiera no podríamos conocerla, y si pudiéramos conocerla no podríamos comunicarla.

Así en este contexto Michel de Montaigne nace en un Castillo, en 1533 en

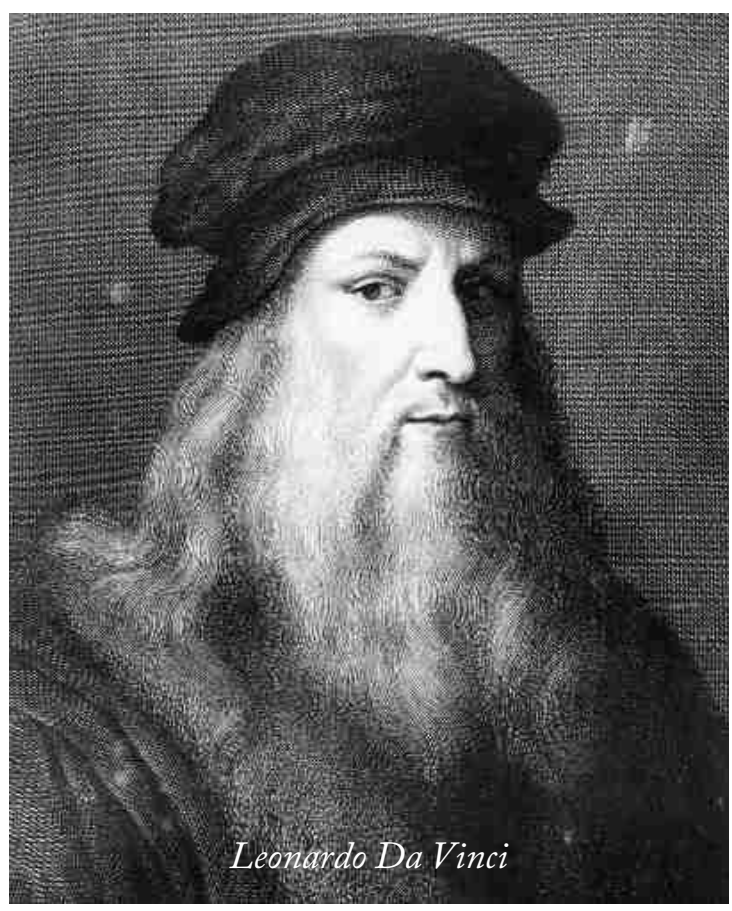

la región francesa de Périgord y muere en Burdeos en 1592. Fue de posición decididamente escéptica o pirrónica y concluye en la irrelevancia e imposibilidad de alcanzar respuestas concluyentes a preguntas de cualquier tipo. Como más se alcanzarán diferentes respuestas o una con mayor probabilidad de veracidad, ideas propuestas por los filósofos escépticos como Carnéades. En la "Apología" muchos de los pasajes de los “Esbozos pirrónicos" se verán reproducidos casi literalmente, y esa defensa encendida de la doctrina escéptica de Sexto Empírico será uno de los golpes decisivos que desde el Renacimiento tardío se dará a la filosofía escolástica. Se cuestionaron la solidez de sus fundamentos metafísicos al utilizar la duda como método. Abriendo el camino por el que seguirá la filosofía moderna. Montaigne llega a la conclusión de que todo conocimiento es subjetivo, tanto que en realidad 
se adapta a las opiniones y gustos de cada uno (a la inversa del pensamiento tradicional). Las últimas ediciones de los "Ensayos" no cambian ya este tono escéptico pero siempre tolerante. El pensamiento de Montaigne es más vasto y más profundo en esta fase, el autor tampoco duda en sincerarse y describirse, habla de sí mismo, a partir de su subjetividad y singularidad personal, para alcanzar lo universal.

Por ello para acercarse a la verdad surge E1 Método de René Descartes (La Haye, Francia, 1596 - Estocolmo, Suecia, 1650). El uso de la razón, la duda metódica, hiperbólica, hasta sus últimas consecuencias. El objetivo es encontrar los enunciados que resistan la duda. Teniendo como etapas; Primera fase de la duda: los sentidos no son de fiar; como saber si no es un sueño, hay que dudar de la razón; en la segunda fase: puedo dudar de que dudo. Yo dudo y al dudar que dudo puedo decir que pienso: pienso luego existo. Primera conclusión: para pensar necesito un Yo, soy un Yo pensante, por lo tanto Existo: que llama Res. Segunda Conclusión: No puedo dudar de las ideas que pienso, existe algo perfecto que son las ideas, $\mathrm{y}$ las ideas de las ideas es dios; concluyo que Dios existe, que es la perfección y debe ser infinito, siendo yo el Res finito. Tercera conclusión: Existen las cosas materiales. Res extensa. Yo pensante, al que llamo ego cogito. Para que sea claro y distinto, debe cumplir las 4 reglas del método de Descartes: Evidencia, Análisis (dividirlo en partes), Síntesis (ordenar); Recapitulación (enumeración)
El método cartesiano, que Descartes propuso para todas las ciencias y disciplinas, consiste en descomponer los problemas complejos en partes progresivamente más sencillas hasta hallar sus elementos básicos, las ideas simples, que se presentan a la razón de un modo evidente, $y$ proceder a partir de ellas, por síntesis, a reconstruir todo el complejo, exigiendo a cada nueva relación establecida entre ideas simples la misma evidencia de éstas. Los ensayos científicos que seguían al Discurso ofrecían un compendio de sus teorías físicas, entre las que destaca su formulación de la ley de inercia y una especificación de su método para las matemáticas. Asíllegamos a David Hume (Edimburgo, 1711 - 1776). Quien parte de la misma perspectiva que Descartes, del escepticismo. Critica al principio de causalidad: El principio de causalidad sólo tiene valor aplicado a la experiencia, aplicado a objetos de los que tenemos impresiones y, por lo tanto, sólo tiene valor aplicado al pasado, dado que de los fenómenos que puedan ocurrir en el futuro no tenemos impresión ninguna. Contamos con la producción de hechos futuros porque aplicamos la inferencia causal; pero esa aplicación es ilegítima, por lo que nuestra predicción de los hechos futuros no pasa de ser una mera creencia, por muy razonable que pueda considerarse. Por ello se puede decir que es la costumbre y no la razón, que nos lleva a pensar que el sol sale todos los días. Así también realiza la Crítica al concepto de sustancia: Hume se preguntará por la validez de la idea de sustancia, y lo hará recurriendo al criterio de verdad que había fijado anteriormente 
en el análisis del conocimiento para determinar la validez de una idea. Según tal criterio, una idea es verdadera si le corresponde una impresión; en caso contrario hemos de considerarla falsa. Ahora bien, sólo hay dos tipos de impresiones: las impresiones de sensación y las impresiones de reflexión. ¿Es la idea de sustancia la "copia" de alguno de esos tipos de impresión? O dicho de otra manera ¿Hay alguna impresión -de sensación o de reflexión- que le corresponda a la idea de sustancia? No, nos dirá Hume. No hay ninguna impresión de sensación que corresponda a la idea de sustancia, ya que esta idea no contiene nada sensible.

En contraposición al despotismo ilustrado de Prusia Immanuel Kant que Nació en Prusia 1724 -1804. Destaca que la ilustración es la audacia de pensar por uno mismo, a diferencia del despotismo que refería: Todo para el pueblo pero sin el pueblo. Dijo Kant he despertado del sueño dogmatico de la razón y se propone encontrar los límites de la razón, con la razón misma. Así Critica a la razón pura: Estética trascendental (sentidos): las condiciones sensibles del conocimiento, que tipo de conocimiento se produce, existen formas a priori de la sensibilidad en el espacio tiempo, cuando tenemos intuiciones puras que producen sensación. El conocimiento del espacio tiempo es lo que nos permite la geometría (espacio) y la matemática (tiempo); la Estética Transcendental (del griego aisthesis: percepción) investiga si la sensibilidad dispone de intuiciones no empíricas, cuáles son éstas y en qué medida funcionan como condiciones del saber empírico y no-empírico. La tesis de Kant dice que "hay dos formas puras de la intuición sensible que son principios del conocimiento a priori, a saber, el espacio y el tiempo". La Analítica trascendental (pensamiento): la sensibilidad a través de la sensación del espacio tiempo produce el fenómeno y este mas el entendimiento del intelecto, permite la misión de comprender. La Analítica de los principios, llamada por Kant también Doctrina transcendental de la facultad de juzgar, comienza con la difícil sección sobre el Esquematismo de los conceptos puros del entendimiento. Ella se ocupa de la pregunta por cómo las categorías se aplican a objetos de la experiencia. Por ejemplo, si la categoría de substancia no puede ser obtenida a partir de la experiencia, entonces ¿cómo reconocemos que en la experiencia estamos frente a una substancia? Kant responde que, entre intuiciones y categorías,

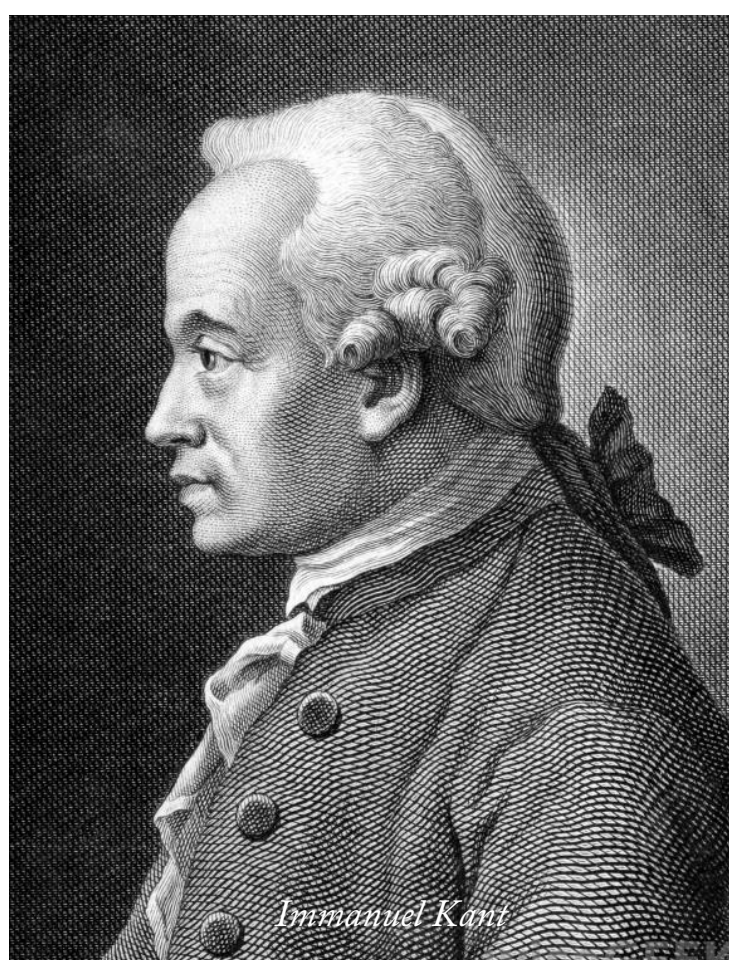


median "esquemas transcendentales" - patrones en la estructura temporal de lo dado intuitivamente que corresponden a cada una de las categorías y que, así, posibilitan la aplicación de éstas. La Dialéctica trascendental (pensamiento del pensamiento): Las representaciones de algo incondicionado, que inevitablemente nos hacemos sobre la base de la dinámica propia de nuestra razón, son, por lo tanto, conceptos puros de la razón. Kant los llama ideas transcendentales. Se dividen en tres clases: las ideas de la psicología racional (metafísica) conciernen al concepto del alma, las de la cosmología racional al concepto del mundo y las de la teología racional al concepto de Dios.

El conocimiento de la realidad es propio de cada uno, lo que no podemos conocer lo llama Noúmeno, la realidad en sí que no podemos alcanzar. El ideal regulatorio, la racionalización de las razas humanas, que Kant propone como proyecto político de la hermandad entre los estados para generar la paz perfecta luego de las guerras. Estableciendo como Ley imperativa categórica: lo racional, incondicional, universal, no material. Sintetizándose Por la positiva "Actúa de modo que la idea máxima que guía tu acción quisieras que se convierta en ley de la humanidad", por la negativa "No hagas a los demás lo que no te gustaría que te hagan a ti". Luego de Kant, la filosofía estaría separada de la física, y la matemática; y nacen así la psicología, la sociología, la economía. Quedándole a la filosofía la metafísica. Se dan las bases para que se inicie $\mathrm{El}$ Positivismo con Comte, Augusto (1798-
1857). Toma ideas del filósofo británico David Hume, del filósofo francés Saint-Simón, y del filósofo alemán Immanuel Kant. En su obra "Sistema de Política Positiva" (1851-1854; 1875-1877), propone una religión de la humanidad que estimulara una benéfica conducta social. La mayor relevancia de Comte, sin embargo, se deriva de su influencia en el desarrollo del positivismo. Como reacción al escepticismo, es la etapa en que se progresa más y más, existe el movimiento demográfico del campo a la ciudad, se crea así la clase obrera, y el marxismo y el socialismo. En Brasil el positivismo se plasma en su bandera de Orden y Progreso. Según Comte, los conocimientos pasan por tres estados teóricos distintos, tanto en el individuo como en la especie humana. La ley de los tres estados: Teológico, Metafísico y Positivo. El teológico o ficticio, pasa a su vez por tres fases: fetichismo, politeísmo y monoteísmo. El metafísico: Busca la explicación en abstracto de las fuerzas de la naturaleza, estado abstracto, es esencialmente crítico, y de transición, Es una etapa intermedia entre el estado teológico y el positivo. E1 Estado Científico o Positivo: Es real, es definitivo. En él la imaginación queda subordinada a la observación. La mente humana se atiene a las cosas. El positivismo busca sólo hechos y sus leyes. No causas ni principios de las esencias o sustancias. Todo esto es inaccesible. El positivismo se atiene a lo positivo, a lo que está puesto o dado: es la filosofía del dato. La mente, en un largo retroceso, se detiene al fin ante las cosas. Renuncia a lo que es vano intentar conocer, y busca sólo las leyes de los fenó- 
menos. Se establece el método científico aplicado a las ciencias naturales, y se lo aplica también a las ciencias sociales. Muchas de las doctrinas de Comte fueron más tarde adaptadas y desarrolladas por los filósofos sociales británicos John Stuart Mill y Herbert Spencer así como por el filósofo y físico austriaco Ernst Mach. Wilhelm Dilthey (1833-1911) es el pensador más importante del historicismo alemán. Su obra más conocida, "la Introducción a las ciencias del espíritu" (1883), da inicio a su proyecto de "crítica de la razón histórica”, que tenía como objetivo encontrar un fundamento epistemológico sólido para las ciencias humanas.

En Jürgen Habermas (Düsseldorf, Alemania, 1929). Encontramos la obra filosófica que trata de recuperar un punto de contacto entre teoría y praxis, frente a la pretendida neutralidad de los saberes positivos y científicos. Según Habermas, no es posible una objetividad ajena a valores e intereses, razón por la cual aquellos saberes resultan reductores, en la medida en que se basan en una razón meramente instrumental. Resultado de ello, siguiendo su crítica, es la creciente burocratización de la sociedad a todos los niveles y la despolitización de los ciudadanos.

Surgen asi los Neo - Positivistas: Bertrand Russerl (1872 - 1970); Alfred Whitehead ( 1861 -1947) ; Rudolf Carnap (1891 -1970); Otto Neurath (1882 - 1945) , Hans Reichenbach (1891 -1953); Ernest Nagel (1901 - 1985); Kurt Godel (1906 -1978) ; Stefan Zweigs (1881-1942). Son los integrantes del denominado Circulo de Viena, Son llamados Neopositivistas Ló- gicos, un grupo de autores, con todas las características de una «Escuela» por sus mutuas relaciones e interdependencias, dedicados a trabajos de lógica y metodología científica y a difundir con ellos una peculiar ideología filosófica conocida como «positivismo lógico». Con estas Características:

- Crítica de la metafísica. Wittgenstein había denunciado que la mayoría de las cuestiones filosóficas, sobre todo las referentes a la metafísica, carecían de sentido si se las examinaba a la luz de un análisis lingüístico. Este postulado fue completamente asumido por la mayoría de los neopositivistas.

- Unificación de las ciencias: proposiciones con sentido. La necesidad de la unificación de las ciencias, sean cuales fuere sus contenidos disciplinares es una de las prioridades del positivismo lógico.

- El problema de la verificabilidad. Este se agudiza cuando se analizan las proposiciones universales, ya que éstas no pueden nunca contrastarse totalmente con lo dado en la experiencia. Lo que hace la ciencia es descubrir leyes, asumen el método científico como experimentación, observación meticulosa, creando relaciones de estas leyes, basados en el cumulo de conocimientos empíricos. Basados en hipótesis que se deben demostrar por el método científico. Teoría, leyes, hipótesis, basado en lo que plantea la física.

Crece así el concepto de La Concepción Heredada: Todos deben tener una estructura axiomática siendo un Axioma: una proposición que se considera tan clara y evidente que no necesita demostración, lo consideramos verdadero. Pero esto solo po- 
demos buscarlo en las matemáticas como concepción ideal. Lo que sería en la filosofía de la ciencia: teorías que deben formularse en forma lógica para ver en qué condiciones son ciertas. $\mathrm{Y}$ el vocabulario lógico: como enunciados de las relaciones de las matemáticas. Ej. Velocidad media. Vocabulario de la observación empírica: tienen que tener datos empíricos en espacio tiempo. Vocabulario teórico: términos que no tienen relación con lo observable, adquiere significado solo si al vocabulario lógico lo podemos relacionar con el observacional. Tenemos así tres tipos de Enunciados con este tipo de vocabulario. Correspondencia: cuando vinculamos, tenemos $\mathrm{Vt}=(\mathrm{V} 1+\mathrm{Vo}) \mathrm{x} 1 / 2$ Enunciado de la velocidad media. Protocolares: Son verdades, buscando la confirmación en la experiencia, verificación empírica, es verdadero siempre y cuando pueda ser verificado por enunciado empírico. Teórico: uso de vocabulario lógico, conceptos teóricos $\mathrm{X}=(\mathrm{v} 1+\mathrm{v} 2+\mathrm{v} 3+\ldots .+\mathrm{vn}) / \mathrm{N}$

Así en la concepción heredada, una Teoría puede ser un Axioma de otra.

Pero no todo entra en este esquema de universalidad, la interpretación de los temas teóricos, si se explican demás tendremos excedente lógico. Que todos lo entendamos no quiere decir que la velocidad media exista, ninguna definición es perfecta, es perfectible. Una definición total es imposible, todas son definiciones parciales, mucho de los términos teóricos, los hacen creer que todos derivan de la experiencia, lo que implica que muchas teorías no han sido construidas de pura observación.
La Teoría del conocimiento: No es lo mismo que teoría científica: que consta de corpus que ha de ser interpretado con recolección de datos, teoría también es lo comprobado y lo que se está investigando. Método científico: interpretación de esas relaciones, interpretación semántica particular de los términos de la teoría. Ejemplo: distintas teorías del átomo. El Criterio de verdad: Desde Aristóteles es la adecuación de la realidad a la idea y así buscar verificarla, ya que no puedo sostener que mis teorías se basan en la realidad. Para saber esto nos mantenemos en el mundo del conocimiento, y no de todo el mundo.

En la Concepción semántica de la verdad: Verdad y verdadero sólo tienen sentido en el uso del lenguaje, ya que no se refieren a la realidad sino a los enunciados, el lenguaje y la realidad no están tan vinculados como creemos. Si consideramos la oración: "la oración la nieve blanca", es verdadera si la nieve es blanca, es falsa sino no lo es, la verdad depende de la realidad. Pero la noción de verdad es la relación de estas partes, relación lógica entre las relaciones y no la realidad. La verdad ya no considera una relación de la lengua con la realidad si no entre vocabularios. Concepto de normalidad: aceptabilidad: Para un conjunto de casos, teoría de conjunto para que sea teoría científica. En ciencias sociales son meras metáforas como la teología, filosofía y la metafísica. Los modelos de la física son reales, pero la física debería reconocer que también trabaja con analogías y metáforas. Ya que se reconoce que lógicamente sintetizar todo el conocimiento o no se puede y hay que utili- 
zar metáforas y analogías en lo denominado: El con.cient. Las leyes se diferencian entre los enunciados explicativos, mayor número de casos y una mayor frecuencia, son circunstanciales hasta que los hechos demuestran lo contrario. Se creía en ciencia que existía la verdad, existía la realidad con el tiempo se alcanzaría el conocimiento total. Por ello surge el Evolucionismo: La realidad existe pero está en constante evolución, evolucionismo que afecta a todos los seres vivos, pero aún no está claro si es para toda la materia. Einstein tenía tiempos negativos pero era determinista, ahora mayoritariamente se cree que no hay determinismo.

Pero John Stuart Mill (1806 -1873): ya había establecido condiciones para la ciencia, el número de enunciados debe ser suficientemente grande, que cubra con la generalización que producimos para los casos observados. $\mathrm{Y}$ no haya enunciado que contradiga la generalización. Podemos actuar así y somos eficientes, y la eficiencia es una legitimización. Se puede ir de lo particular a lo General, es más, de la experiencia podría justificarse una teoría, pero de esta debería salir una teoría.

Análogamente El Inductivismo de Karl Popper (1902 - 1994): para que sea ley, se deben establecer conexiones necesarias entre los términos. La ciencia partiría de la acumulación de datos, enunciados que describen la experiencia, a partir de este conjunto de datos, cuando tratamos de establecer relaciones estables necesarias que permitan predecir. Muchos datos no son infinitos datos, la realidad infinita en infinitos cambios, por ello se debe delimitar. Entonces se ha- bla de Inconmensurable que no es infinito. Las investigaciones son tendientes a ser deterministas, incluso las ciencias sociales. Inferencia causal: Si lo hago varias veces $\mathrm{y}$ funciona, digo que es así. Pero esto no necesariamente va a ser así la próxima vez, esta es la crítica al inductivismo. La inducción genera problemas con la noción de infinito y de cero, el aumento de casos no aumenta la probabilidad de acercarme a la verdad, si el universo es infinito cualquier cantidad es poco para experimentar. Carga teórica: Para ser teoremas y que teoría necesitaría para recolectar datos. Una pre comprensión: todas las teorías que empiezan con la recolección de datos, pero toda teoría se basa en datos. No necesariamente se llega a la misma teoría, al final que al principio, no hay observadores objetivos porque todos los datos están basados en una pre comprensión.

Popper, para decidir cuándo es válido el inductivismo, para que no se acepte parte de presunción de posibilidades, la teoría verdadera será cuando sepa cuáles son los límites de aplicación, sepamos falsearla, falsasionismo. La ciencia ya no trabaja solo con el inductivismo, recolección, análisis teóricos, si no con una sucesión constante de conjeturas audaces y futuras revoluciones. La teoría con que partimos nos ayuda entonces ya que sí estas teorías se comprueban, tiene excedentes para las teorías de las que provienen. Para falsearla con un solo caso Popper se conforma porque luego saldrán más falsaciones. El Criterio de demarcación: Dentro y fuera de la ciencia las sucesivas falsacciones producen un avance en la ciencia; permiten mantener simultánea- 
mente varias teorías, no necesito mantener solo una, aunque sean diferentes entre sí se van debilitando. Como ejemplo tenemos la cantidad de años que sobrevivió el geocentrismo, Einstein no pudo abandonar el determinismo, pero dio las bases para ello, no pudo abandonar una teoría previa. Así Lakatos distingue un núcleo y un cinturón de protección, la sucesión de teorías que mantienen un núcleo igual, ejemplo la física, es el programa de investigación: paradigma. Cuando el número de anomalías es mayor a los que confirman ha dejado de ser verdadera. Por lo tanto el criterio pasa nuevamente a ser subjetivo de la comunidad científica que es la que define internamente y que genera consensos. La historia de la ciencia tiene periodos de estabilidad e inestabilidad, la ciencia extraordinaria. Produce el cambio de paradigma, de estos cuatro elementos: leyes, hipótesis, materias empíricas, teorías.

La Nueva Alianza: Ilya Prigogione (1917-2003): Toda la realidad la buscó desde la físico química, en la evolución de estas. Afirma que para preguntar la ciencia debe ayudarse de la filosofía, es decir la interpretación sobre la realidad. En la Nueva alianza, todo debe ser interdisciplinario, supone una ruptura y un avance mayor, dándole una mayor participación de la estabilidad y la inestabilidad y el azar, la intuición y el cambio, en armonía con la naturaleza.

\section{Conclusión}

En este trabajo se han tenido que seleccionar los autores de acuerdo a su grado de trascendencia en el conocimiento predominante, dejándose de lado otros autores que podrían ser muy valiosos e incluso representar en sus ideas, pensamientos más cercanos a la naturaleza. De los filósofos analizados Desde Thales de Mileto, quien es considerado el Padre de la filosofía, que obtuvo gran parte de sus conocimientos iníciales en base a los estudios que realizó en Memphis en el antiguo Egipto. Dado que antes de Thales predominaba, el conocimiento místico y supersticioso, y por ello es considerado el primero que ha realizado un estudio serio y meticuloso de la realidad en busca de la verdad, consideraba desde la naturaleza al agua como el origen de todas las cosas. La filosofía de la ciencia ha recorrido un largo camino, del cual podemos decir que no hay casi avances disruptivos, sino profundización de los caminos ya transitados. Resultado de ello es que el conocimiento occidental se ha basado principalmente en la manera metodológica de abordarlo desde la física, dejando de lado muchas veces conocimientos que hoy se rescatan a través de la Nueva Alianza de Prigogine y Stengers, que si bien en este caso nacen del conocimiento de la química, se extienden a numerosas ramas del conocimiento como la filosofía, sociología, economía y la administración etc., ya que dejando de lado el determinismo se puede pensar en un universo en constante transformación, como así también en nuestra escala social.

$\mathrm{Si}$ nos basamos principalmente en el avance del conocimiento científico, pero también en el conocimiento producido por la intuición, la estabilidad y la inestabilidad que genera un cambio para volver nueva- 
mente a un equilibrio, y así sucesivamente. Se concluye que se debe volver a un equilibrio, que no se debería haber abandonado , entre el conocimiento empírico y la metafísica, que ha permitido a lo largo de los siglos que se desarrolle más rápidamente el conocimiento científico en occidente pero también ha generado en la actualidad efectos indeseados, como un exceso de individualismo, alienación y un alejamiento del ser humano de la naturaleza, por lo que hay que volver a considerar lo complejo, rompiendo con esa simplicidad Popperiana, que tanto el positivismo como el Marxismo, lo tomaron del determinismo. El futuro no está escrito por ninguna ley física o de la historia, sino que la construimos día a día los hombres y mujeres que participamos

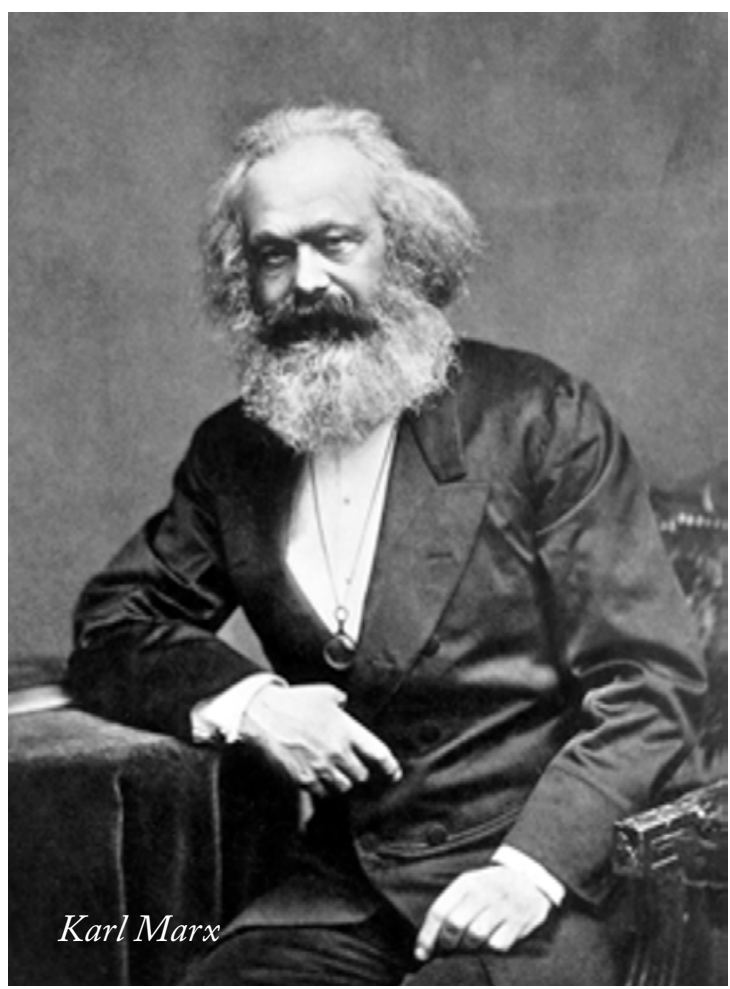
de esta vida en común en nuestra casa, la tierra. Converge en este sentido la encíclica de la Iglesia católica: laudato si (2015) del Papa Francisco en el que desacraliza el proceso lógico racional ya que este abarca y posee el objeto que se halla fuera de sí a través del método científico y luego lo encuentra totalmente disponible para su manipulación, con su experimentación, que ya es explícitamente técnica de posesión, dominio y transformación de la naturaleza. Es como si el sujeto se hallara frente a lo informe totalmente disponible. Si bien

la intervención humana en la naturaleza siempre ha acontecido, esta durante mucho tiempo, hasta la revolución industrial, tuvo la característica de acompañar, de plegarse a las posibilidades que ofrecen las cosas mismas. Por lo que habría que cambiar el paradigma tecnocrático, para considerar la multidisciplinariedad del conocimiento de un ecosistema ambiental, económico y social. Hacia cuyo objetivo se podrían dirigir nuevas etapas o investigaciones. 
5. Bibliografía

Aristóteles. (1994). Metafísica. (V. Garcia Yebra, Trad.) Madrid: Gredos.

Chalmers, A. (1987). Que es esa cosa llamada Ciencia? (5 ed.). Buenos Aires: Siglo XXI.

Echeverría, J. (1999). Introducción a la metodología de la ciencia. La filosofía de la ciencia en el siglo XX. Madrid: Cátedra.

Eduardo, M. (2006). Redes de Conocimiento, construcción dinámica y gestión. Buenos Aires: Mario --Albornoz y Claudio Alfaraz editores.

Engels, F. (1970). El origen de la familia, la propiedad privada y el estado. Madrid: Fundamento.

Hanson, N. R. (1977). Patrones de descubrimiento. Observación y explicación. Madrid: Alianza.

Heidegger, M. (2002). Interpretaciones fenomenológicas sobre Aristoteles. Madrid: Trotta.

Hume, D. (1961). Treatise of human Nature. (E. Larroyo, Trad.) London: Porrúa

Julian, M. (1980). Historia de la Filosofía (32 ed.).
Madrid: Revista de Occidente

Khun, T. (1962). La estructura de las revoluciones científicas. Madrid: F.C.E.

Klimovsky, G. (1990). Estructura y validez de las teórias científicas. Buenos aires: Eudeba.

Lakatos, I. (1993). La metodología de los programas de investigación. Barcelona: Alianza. Mario, B. (1980). La Investigación Científica. Su estrategia y su Filosofía (7 ed.). Barcelona: Ariel. Papa, F. (2015). Carta Encíclica Laudato Si-sobre el cuidado de la casa común-. Iglesia Católica.Vaticano: Tipografia vaticana.

Pineda Elia, B., \& Alvarado, E. L. (2008). Metodología de la Investigación (3 ed.). Whasington: Organización Panamericana de la salud.

Popper, K. (1972). Conocimiento Objetivo. Madrid: Tecnos.

Prigogine Ilya y Stengers Isabelle. (2004). La Nueva Alianza: Metamorfosis de la ciencia. Madrid: Alianza. 